Stoehr, M. U., B. L. Orvar, T. M. Vo, J. R. Gawley, J. E. WeBber and C. H. NewTON (1998): Application of a chloroplast DNA marker in seed orchard management evaluations of Douglas-fir. Can J For Res 28: 187-195.

Stoenr, M. U. and C. H. Newton (2002): Evaluation of mating dynamics in a lodgepole pine seed orchard using chloroplast DNA markers. Can J For Res 32: 469-476.

Stoenr, M. U., J. E. Webber, C. C. A. Hollefreund and R. A. PAinter (2004): Potential pollen contamination effects on progeny from an off-side Douglas -fir seed orchard: 9-year field results. Can J For Res 34: 981-984.

TAKeuchi, H., H. Handa, T. Ohguro and M. OkAmuRa (1989): Selection of resistant pine trees to the pine-wood nematode in Shikoku. Bull For Tree Breed Inst 7: 119-143 (in Japanese with English summary).

TANG, D. Q. and Y. IDE (2001): Genetic variation in fruitfulness in a Hinoki (Chamaecyparis obtusa Endl.) seed orchard and its impact on the maintenance of genetic diversity in seedlots. Journal of Forest Research 6: 67-72.

Terada, M., T. Toda and T. Noguchi (1997): The selection of the nematode-resistant candidates from the damaged forest in the cold district. The control trees of the inoculation test in the breeding project on resistance to pine- wood nematodes in Tohoku. Bull Tohoku For Tree Breed Inst 27: 57-58 (in Japanese). ${ }^{*}$

Toda, T., Y. Fujimoto, K. Nishimura, H. Yamate and S. FuYuno (1989): Selection of resistant pine trees to the pine-wood nematode in Kyushu. Bull For Tree Breed Inst 7: 145-178 (in Japanese with English summary).

ToDA, T. (2004): Studies on the breeding for resistance to the pine wilt disease in Pinus densiflora and $P$. thunbergii Bull For Tree Breed Inst 20: 83-217 (in Japanese with English summary).

Toda, T., M. TAJime, K. Nishimura and H. TAKeuchi (1993): Resistance breeding to the pine wood nematode in Kyushu district. - Progress of study after selection of the resistance clones - Bull For Tree Breed Inst 11: 37-88 (in Japanese with English summary).

Watanabe, A., M. G. Iwaizumi, M. Ubukata, T. Kondo, C. LIAN and T. HoGETU (2006): Isolation of microsatellite markers from Pinus densiflora Sieb. et Zucc. using a dual PCR techniques. Mol Ecol Notes 6: 80-82.

WheELER, N. C. and K. S. JECH (1992): The use of electrophoretic markers in seed orchard research. New Forests 6: 311-328.

*) The titles are approximate translations of the original Japanese title by the authors of this paper.

\title{
Genetic Variation in Seed Size and Germination Patterns and their Effect on White Spruce Seedling Characteristics
}

\author{
By S. Carles ${ }^{1), *}$, M. S. Lamhamedi ${ }^{2)}$, J. Beaulieu ${ }^{3)}$, D. C. Stowe ${ }^{1)}$, F. Colas $^{2)}$ and H. A. Margolis ${ }^{1)}$
}

(Received $4^{\text {th }}$ December 2007)

\begin{abstract}
We determined the degree to which families differ in seed and germination characteristics and examined the extent to which these characteristics influence the early growth of 75 open-pollinated white spruce families. Seed

\footnotetext{
1) Centre d'étude de la forêt (CEF), Faculté de foresterie, de géographie et de géomatique, Pavillon Abitibi Price, Université Laval, 2405 rue de la Terrasse, Québec, QC, G1V 0A6, Canada. des Ressources naturelles et de la Faune, 2700 rue Einstein, Québec, QC, G1P 3W8, Canada. an Wood Fibre Centre, 1055 rue du P.E.P.S., P.O. Box 10380, Sainte Foy, Québec, QC, G1V 4C7, Canada. 418-656-5262. E-Mail: sylvie.carles@sbf.ulaval.ca
}

2) Direction de la recherche forestière, Forêt Québec, ministère

3) Natural Ressources Canada, Canadian Forest Service, Canadi-

*) Corresponding Author: Sylvie Carles. Tel: 418-656-2629, Fax:
\end{abstract}

characteristics (1000-seed weight, length, width, area, volume) were measured for 400 seeds per family. Germination variables (germination capacity, peak value, germination value) were determined for each of the 75 families under controlled conditions and germination patterns were modelled using the Weibull function. Seedling characteristics (height, diameter, shoot and root dry weights) were measured at the end of the first and second growing seasons under standard nursery cultural practices. Statistically significant family variation $(p<0.0001)$ was found for all seed characteristics and germination variables measured. The between-family variance explained $23 \%$ to $98 \%$ of the total variance of morphological and physiological seed characteristics. Family differences at the seed stage explained up to $33 \%$ (root dry weight) and $12 \%$ (shoot dry weight) of the family differences observed at the one-year and two-year seedling stages, respectively. Since, in this study based 
on a comparison of family means, a maximum of only $12 \%$ of the family differences observed at the two-year seedling stage were explained by the effect of seed size, a selection for families with better juvenile characteristics could be envisaged without considering the maternal effect of seed size.

Key words: Weibull function, genetic variation, repeatability, heritabilities, maternal effect, Picea glauca.

\section{Introduction}

White spruce (Picea glauca [Moench] Voss) is one of the most widely distributed conifers in North America (NienstaedT and Teich, 1972) and is adapted to a wide range of edaphic and climatic conditions (NIENSTAEDT and ZASADA, 1990). It exhibits high genetic variability for characteristics such as wood density, ring width (CORRIVEAU et al., 1991), height, branch number, growth duration, and growth rate (LI et al., 1993). White spruce seedlings exhibit significant inter-family (KHALIL, 1985; Li et al., 1993; RWEYONGEZA et al., 2005) and clonal (LAMHAMEDI et al., 2000) variability for many morphophysiological characteristics. To date, this variability at the provenance and family levels has been used for the early selection of older tree traits, rather than as a tool for improving seedling quality. KHALIL (1985) estimated family heritability for root length and root dry weight 13 months after sowing. He found a heritability for root length of $0.80( \pm 0.65)$, whereas family heritability for root dry-weight family was close to zero. RWEYONGEZA et al. (2005) found a moderate $(0.453 \pm 0.107)$ family heritability for root dry weight of 3-year-old white spruce seedlings. Root growth is critical to the establishment of planted seedlings because they have to absorb water from the soil to meet shoot evaporative demand and limit post-planting water stress (GROSSNICKLE, 2005). A root system that is well developed under nursery conditions increases a seedling's chance of survival after planting. To determine whether genetic gains for desired seedling root characteristics are achievable, it is first necessary to estimate the genetic parameters for these traits.

Growth of white spruce seedlings is known to be positively correlated with seed size (KHALIL, 1981; LAMHAMEDI et al., 2006). PARKER et al. (2006) and WRIGHT et al. (1992) showed that root dry weight and root length increased with seed weight in pines. LAMHAMEDI et al. (2006) also reported that seedlings from large seeds (diameter $\geq 1.75 \mathrm{~mm}$ ) had greater root dry weight than those grown from small seeds $(1.5 \mathrm{~mm} \leq$ diameter $<1.75 \mathrm{~mm}$ ). Seed size is influenced by the morphological characteristics, such as diameter (CARON et al., 1993) and height-to-diameter ratio (NolAND et al., 2006), and the genotype of the mother tree (CASTRO, 1999), and can lead to observable differences among families at the seedling stage (SORENSEN and CAMPBELL, 1993). Variation in seed size may cause an overestimation of genetic parameters and expected genetic gains of seedling characteristics (SoRENSEN and CAMPBELl, 1993). St. Clatr and ADAMs (1991) found that family differences in seed weight explained $23 \%$ of the variation in total dry weight of Douglas-fir seedlings. Family-level studies often investigate the relationship between seed-size class and seedling characteristics. This may mask some of the variation that appears when absolute seed size values are used rather than seed size classes (CHAISURISRI et al., 1992). Estimating variation among families for absolute seed size values, such as seed weight, length or width, and its effect on variation in seedling characteristics provides a measure of the degree to which the observed variation in seedlings is due to maternal effects.

Like seed size, germination can influence seedling characteristics. PARKER et al. (2006) suggested that early emergence accounted for $27 \%$ of variation in total dry mass of 8-week-old eastern white pine (Pinus strobus L.). DUNLAP and BARNETT (1983) showed that the speed of germination contributed substantially to size variation in loblolly pine (Pinus taeda L.) seedlings, with faster germinating seeds producing larger seedlings. Seed germination variables exhibit both genetic and environmental components (FARMER, 1997). CARON et al. (1993) and KRAKOWSKI and El-KASSABY (2005) found that white spruce families had highly variable germination percentages and rates of germination. Single-value indices, such as germination and peak values (CZABATOR, 1962), germination capacity, or time to reach $50 \%$ of germination are important descriptive characteristics. In addition, the pattern of seed germination should also be modelled (BROwN and MAYER, 1988) so that the family variability in germination curves can be studied and the relationship between germination patterns and seedling characteristics for different families can be compared.

In the present study, we examined the extent to which seed size and germination pattern influenced early growth of white spruce families. Our objectives were to: (1) determine the degree to which families differ in seed and germination characteristics under controlled conditions, (2) mathematically model the pattern of seed germination and study its variation among families, and (3) determine the relationship between morphological and physiological seed characteristics and the morphology and growth characteristics of seedlings under nursery conditions.

\section{Materials and Methods}

\section{Genetic material}

Cones were collected on 75 plus-trees in the Québec first-generation breeding orchard located at the Cap Tourmente National Wildlife Reserve $\left(47^{\circ} 04^{\prime} \mathrm{N}\right.$, $\left.70^{\circ} 50^{\prime} \mathrm{W}\right)$. This breeding orchard is an assembly of 100 plus-trees from 17 provenances sampled in Quebec and Ontario. The original latitude and longitude ranges of these provenances were from $44^{\circ} 10^{\prime} \mathrm{N}$ to $46^{\circ} 55^{\prime} \mathrm{N}$ and $72^{\circ} 56^{\prime} \mathrm{W}$ to $79^{\circ} 20^{\prime} \mathrm{W}$ (BEAULIEU, 1996). Cones for the first 68 families were collected in the fourth week of August, 1996 and those of the remaining families were collected in the fourth week of August, 2001. They were then matured at ambient temperature for approximately two months, after which seeds from each open-pollinated family were extracted, cleaned and stored separately at $-20^{\circ} \mathrm{C}$. 


\section{Seed characteristics}

Four hundred randomly selected seeds per family were measured using WinSeedle image analysis software (Regent Instruments, Québec, QC, Canada). The types and measurements of seed characteristics were as follows:

LS - Straight length (mm) - length measured from end to end in a straight line,

WS - Straight width ( $\mathrm{mm})$ - maximum width measured perpendicular to straight length,

WLR - Width to length ratio - straight width as a fraction of straight length,

AP - Projected area $\left(\mathrm{mm}^{2}\right)$ - area of the projected scanned seed image,

AE - Ellipsoidal area $\left(\mathrm{mm}^{2}\right)$ - estimated seed surface area from projected area and an ellipsoidal crosssection model,

VE - Ellipsoidal volume $\left(\mathrm{mm}^{3}\right)$ - estimated seed volume from projected area and an ellipsoidal crosssection model, and

SW - 1000-seed weight (g) - determined by calculating the average weight of eight replicate samples of 100 seeds each, following the International Seed testing Association (ISTA) methodology (INTERNATional Seed Testing Association [ISTA], 1999). The 1000-seed weight was measured for only 70 of the 75 families due to seed shortage for the five remaining families.

\section{Germination variables under laboratory conditions}

Seeds were first cold-stratified at $+4{ }^{\circ} \mathrm{C}$ for 21 days to mimic the standard white spruce seed treatment for commercial container seedling production in Quebec. After the chilling period, seeds were subjected to germination test following ISTA (1999) procedures. Petawawa germination boxes were placed in an incubator (Conviron G-30, controlled Environments Ltd., Winnipeg, MB, Canada) set at an alternating temperature of $28^{\circ} \mathrm{C}$ for 16 hours followed by $20^{\circ} \mathrm{C}$ for 8 hours. Light at approximately 1000 lux was provided during the high temperature period using cool-white fluorescent tubes. The relative humidity in the incubator was maintained at $85 \%$ $( \pm 2 \%)$ throughout the entire test. The number of germinants was recorded $7,9,11,14,16,18,21,23,25$ and 28 days from the beginning of the germination test. A seed was considered to have germinated when the cotyledons became visible [stage 2 sensu WANG (1973)]. The following seed germination variables were assessed:

GC - Germination capacity - percentage of seeds germinated by the conclusion of the experiment,

PV - Peak Value - mean daily number of germinants of the most vigorous seeds, and

GV - Germination Value - a combined index of germination speed and completeness, equivalent to PV multiplied by mean daily germination over the entire experiment (CZABATOR, 1962).

For each family, the germination capacity was validated against the acceptable range specified by ISTA (1999). Three families (19, 44 and 55) were rejected on this basis. All data relating to germination are therefore based on the remaining 72 families.

\section{Seedling characteristics under nursery conditions}

To assess seedling characteristics over a 2-year period, a randomized complete block design consisting of six replications was set up in an unheated polyethylene tunnel at the Centre de Production de Plants Forestiers du Québec (CPPFQ), a private forest nursery located in Sainte-Anne-de-Beaupré, Québec, Canada $\left(47^{\circ} 02^{\prime} \mathrm{N}\right.$, $70^{\circ} 55^{\prime} \mathrm{W}$ ). For each family, 18 containers (3 containers $\mathrm{x}$ 6 blocks) were used. Buffer zones of two rows of containers were left between adjacent blocks and along the edges of the experimental area.

Seedlots were stratified by imbibition under running water for 24 hours before being stored in non-hermetically sealed plastic containers at $4{ }^{\circ} \mathrm{C}$ for 21 days. The seeds were manually sown on June 7, 2004 into IPL 15320 containers (15 cavities, $320 \mathrm{~cm}^{3}$ per cavity; IPL ${ }^{\circledR}$, Saint Damien, Québec, QC, Canada) filled with a peat:vermiculite (3:1) growing medium. Three seeds were sown per cavity. During the week of July 12, 2004 (six weeks after sowing), the seedlings were thinned to one seedling per cavity. Empty cavities were filled with transplanted seedlings from the same family. The seedlings were subjected to standard cultural practices during their first two years of growth. Substrate water content was maintained near $40 \%(\mathrm{v} / \mathrm{v})$ during the two growing seasons. During the first growing season, plants were fertilized between July 7 and September 27 . The total quantities of $\mathrm{N}, \mathrm{P}$ and $\mathrm{K}$ applied over the growing season were 60.7, 19.7 and $38.1 \mathrm{mg} / \mathrm{plant}$, respectively. During the second growing season, plants were fertilized between May 10 and September 22, using seasonal totals of 402.3, 99.8 and $154.2 \mathrm{mg} / \mathrm{plant}$ for $\mathrm{N}, \mathrm{P}$ and $\mathrm{K}$, respectively. The polyethylene tunnel cover was removed on October 13, 2004, as is customary at the end of the first growing season, and was not used during the second growing season.

Three seedlings per family per block (plot) were destructively sampled at the end of both the first (October 25, 2004) and second (October 21, 2005) growing seasons. The following seedling characteristics were measured:

$\mathrm{H} 1$ and $\mathrm{H} 2$ - seedling height $(\mathrm{cm})$ at the end of the first (1) and second (2) growing seasons,

$\mathrm{D} 1$ and D2 - root collar diameter $(\mathrm{mm})$ at the end of the first (1) and second (2) growing seasons,

$\mathrm{S} 1$ and $\mathrm{S} 2$ - shoot dry weight (g) at the end of the first (1) and second (2) growing seasons,

$\mathrm{R} 1$ and $\mathrm{R} 2$ - root dry weight $(\mathrm{g})$ at the end of the first (1) and second (2) growing seasons,

RSR1 and RSR2 - root to shoot ratio at the end of the first (1) and second (2) growing seasons,

$\mathrm{RL} 1$ - total root length $(\mathrm{cm})$ at the end of the first (1) growing season,

$\mathrm{RD} 1$ - average root diameter $(\mathrm{mm})$ at the end of the first (1) growing season, and

RAP1 - root projected area $\left(\mathrm{cm}^{2}\right)$ at the end of the first (1) growing season.

At the end of the first growing season, root architectural characteristics (RL1, RD1, and RAP1) were deter- 
mined for one seedling per family per block (for 3 of the 6 blocks) using image analysis software (WinRhizo, Instruments Régent Inc., Québec, QC, Canada) according to the procedures developed by LAMBANY and VEILleuX (1999).

\section{Statistical Analyses}

\section{Seed characteristics}

Data were subjected to analysis of variance (ANOVA) using the following linear model:

$$
Y_{i j}=\mu+f_{i}+e_{i j}
$$

where $Y_{i j}$ is an observation made on the $j^{\text {th }}$ seed from the $i^{\text {th }}$ family; $\mu$ is the overall mean; $f_{i}$ is the random effect of the $i^{\text {th }}$ family; and $e_{i j}$ is the random residual effect associated with the $j^{\text {th }}$ seed from the $i_{t h}$ family. All analyses of variance were carried out using PROC MIXED (SAS Institute Inc., Cary, NC, USA). Family means were calculated for each seed characteristic. As characteristics were measured on many seeds from each mother tree, the total phenotypic variance could be partitioned into between- and within-family variances. The ratio of the between-family variance component to the total phenotypic variance is the intra-class correlation $(t)$. When data are repeated measurements of the same individual, as is the case for seeds collected from the same tree, the intra-class correlation is known as the repeatability $(\mathrm{Re})$ (FALCONER, 1981), which is calculated as:

$$
R e=\frac{\sigma_{G}^{2}+\sigma_{E}^{2}}{\sigma_{P}^{2}}
$$

where $\sigma_{G}^{2}$ is the genetic variance, $\sigma_{E}^{2}$ the general environmental variance associated with permanent and nonlocalized influences, and $\sigma_{P}^{2}$ the phenotypic variance. Since all mother trees were located in the same seed orchard, we assumed that the general environmental variance was not large enough to be considered significant. Thus, in our case, $\sigma_{G}^{2}$ and $\sigma_{E}^{2}$ were confounded, so that

$$
R e=\frac{\sigma_{f}^{2}}{\sigma_{f}^{2}+\sigma_{e}^{2}}
$$

where $\sigma_{f}^{2}$ is the family variance and $\sigma_{e}^{2}$ is the special environmental variance associated with temporary and localized influences (FALCONER, 1981).

The standard error of seed characteristic repeatability was evaluated as described by BECKER (1985).

\section{Germination variables}

The cones of open-pollinated families 69 to 75 were collected five years later than those of the 68 other families. Simpson et al. (2004) found that germination of white spruce seeds stored at $-20^{\circ} \mathrm{C}$ for 24 years was not significantly different from germination of the same seedlots evaluated immediately after collection. For this reason, the effect of collection year was not considered in the statistical analyses.

Data were submitted to an analysis of variance (ANOVA) using a linear model similar to model [1]. A mixed model was used to estimate the best linear unbi- ased predictor (BLUP) for the mean of each germination variable of each family (LITTEL et al., 1996; RoBINSON, 1991).

Germination is a feature of the embryo, which consists of diploid tissue resulting from parental union, thus enabling family heritabilities for germination variables (GC, PV, GV) to be estimated as follows:

$$
h_{f}^{2}=\frac{\sigma_{f}^{2}}{\left(\frac{\sigma_{e}^{2}}{4}\right)+\sigma_{f}^{2}}
$$

where $\sigma_{f}^{2}$ is the family variance component, and $\sigma_{e}^{2}$ the error variance component.

Standard errors of the heritability estimates were derived from Dickerson's method as suggested by DIETERS et al. (1995):

$$
S . E .\left(h_{f}^{2}\right)\left(\frac{\sigma_{f}^{2}}{\left(\frac{\sigma_{e}^{2}}{4}\right)+\sigma_{f}^{2}}\right)=\frac{S . E \cdot \sigma_{f}^{2}}{\left(\frac{\sigma_{e}^{2}}{4}\right)+\sigma_{f}^{2}}
$$

\section{Modelling of germination curves}

To describe the pattern of seed germination, we used the Weibull function (BONNER and DELL, 1976) to model cumulative seed germination of individual families based on the four 100-seed germination test replications as follows:

$$
F(x)=1-e^{\left\{-\left[\frac{(x-a)}{b}\right]^{c}\right\}}
$$

where $F(x)$ is a cumulative distribution function which corresponds to the proportion of germination observed at time $x ; a$ estimates the earliest time at which the proportion of germinated seed is greater than zero; the parameter $b$ serves as a multiplier. In a Weibull function, $a$ and $b$ are estimated so that approximately $63 \%$ of the germination has taken place within the timeframe $a+b$. Hence, $b$ is the time beyond a that is required for $63 \%$ of the seeds to germinate (BONNER and DELL, 1976). The parameter $c$ defines the shape of the distribution. Accelerated failure time models were used (PROC LIFEREG procedure) (SAS Institute Inc., Cary, NC, USA) to estimate $b$ and $c$ for each family germination curve. The value of $a$ was set to 7.5 days because no seed had germinated before day 7 , whereas all of the families had started to germinate by day 9 . Parameters $b$ and $c$ were then subjected to an ANOVA using model [1]. Heritability of family means and their standard errors were estimated as described earlier (Eq. [4] and [5]).

\section{Seedling characteristics}

Because a high spatial heterogeneity was observed, seedling data were adjusted using the Papadakis method (PAPADAKIS, 1937). This method makes it possible to reduce the spatial variation of phenotypic values by adjusting individual values on the basis of the performance of their nearest neighbours. These statistical analyses were performed with Diogene quantitative genetics software (BARADAT and LABBÉ, 1995). 
Data were then subjected to an ANOVA using the following mixed model:

$$
Y_{i j k}=\mu+f_{i}+b_{k}+v_{i k}+e_{i j k}
$$

where $Y_{i j k}$ is an observation made on the $j^{\text {th }}$ seedling from the $i^{\text {th }}$ family in the $k^{\text {th }}$ block; $\mu$ is an overall mean; $f_{i}$ is the random effect of the $i^{\text {th }}$ family; $b_{k}$ is the random effect of the $k^{\text {th }}$ block; $v_{i k}$ is the random effect of the interaction between the $i^{\text {th }}$ family and the $k^{\text {th }}$ block; and $e_{i j k}$ is the residual random effect associated with the $j^{t h}$ seedling from the $i^{\text {th }}$ family in the $k^{\text {th }}$ block.

For each seedling characteristic, the mean of each family was estimated using best linear unbiased prediction (BLUP).

\section{Seed vs seedling characteristics}

To test whether germination pattern had a significant effect on seedling characteristics an ANOVA was performed using the following mixed linear model:

$$
Y_{i j k}=\mu+\alpha_{i 0} m_{i}+\alpha_{i 1} c_{i}+f_{i}+b_{k}+v_{i k}+e_{i j k}
$$

where $Y_{i j k}$ is an observation made on the $j^{\text {th }}$ seedling from the $i^{\text {th }}$ family in the $k^{\text {th }}$ block; $\mu$ is the overall mean; $m_{i}$ is the fixed effect of the parameter $b$ of the Weibull function of the ith family; $c_{i}$ is the fixed effect of the parameter $c$ of the Weibull function of the $i^{t h}$ family; $\alpha_{i 0}$ and $\alpha_{i 0}$ are the slope of the linear relationship between the observation $Y_{i j k}$, and, respectively, the parameter $b$ and $c$ of the Weibull function; $f_{i}$ is the random effect of the $i^{\text {th }}$ family not accounted by $m$ and $c ; b_{b}$ is the random effect of the $k^{\text {th }}$ block; $v_{i k}$ is the random effect of the interaction between the $i^{\text {th }}$ family and the $k^{\text {th }}$ block; and $e_{i j k}$ is the residual random effect associated with the $j^{\text {th }}$ seedling from the $i^{\text {th }}$ family in the $k^{\text {th }}$ block.

The relationships between BLUP family means of seedling and seed characteristics were examined by Pearson's product-moment correlation coefficients and a series of forward addition stepwise multiple regression analyses. Each regression considered one seedling characteristic as the dependent variable and four seed characteristics (SW, LS, WS, and GV) as independent variables in the following model:

$$
Y=\beta_{0}+\beta_{1} S W+\beta_{2} L S+\beta_{3} W S+\beta_{4} G V+\varepsilon
$$

where $Y$ is the BLUP family mean of a seedling characteristic; $\beta_{0}$ to $\beta_{4}$ are the regression parameters to be estimated; and $S W, L S, W S$ and $G V$ are the family means of 1000-seed weight, seed length, seed width and germination value, respectively. Stepwise multiple regression analysis retained only the explanatory variables whose contribution to the model fit was significant at $15 \%$ level of probability. Finally, we investigated the degree to which family heritability of seedling characteristics may be overestimated by comparing estimates based on variance components before and after adjusting seedling size for the seed effect for H1Y, H2Y, R1 and R2. To do this, seed characteristics that were retained in the stepwise multiple regression analysis were entered in the ANOVA (Eq. [8]) as covariates. Heritability for family means and their respective standard errors were then estimated as previously described (Eq. [4] and [5]) with and without taking account of the pre-existing effect of between-family seed variability.

\section{Results}

\section{Seed, Germination and Seedling Characteristics}

Table 1 shows the overall mean, the range of family means, the repeatability, the heritability and the family

Table 1. - Overall mean, range of family means, repeatability of seed characteristics, family heritability of germination vari-

\begin{tabular}{|c|c|c|c|}
\hline Characteristics $^{\mathrm{a}}$ & & Mean & \\
\hline Seed & & & $\boldsymbol{R e}$ \\
\hline $\mathbf{L S}^{\mathbf{b}}$ & 2.83 & $(2.38-3.36)$ & $\mathbf{0 . 5 1 4 2} \pm 0.0411$ \\
\hline $\mathbf{W S}^{\mathbf{b}}$ & 1.56 & $(1.32-1.84)$ & $\mathbf{0 . 4 0 4 3} \pm 0.0412$ \\
\hline $\mathbf{W L R}^{\mathrm{b}}$ & 0.55 & $(0.49-0.62)$ & $\mathbf{0 . 2 2 8 6} \pm 0.0293$ \\
\hline $\mathbf{A} \mathbf{P}^{\mathrm{b}}$ & 3.23 & $(2.39-4.36)$ & $\mathbf{0 . 5 3 0 4} \pm 0.0398$ \\
\hline $\mathbf{A} \mathbf{E}^{\mathbf{b}}$ & 7.44 & $(5.54-10.04)$ & $\mathbf{0 . 5 2 4 9} \pm 0.0411$ \\
\hline $\mathbf{V} \mathbf{E}^{\mathbf{b}}$ & 0.82 & $(0.53-1.29)$ & $\mathbf{0 . 4 9 6 0} \pm 0.0413$ \\
\hline $\mathbf{S W}^{\mathfrak{e}}$ & 2.59 & $(1.64-3.85)$ & $0.9768 \pm 0.0041$ \\
\hline Germination & & & $h_{f}^{2}$ \\
\hline $\mathbf{G C}^{\mathbf{d}}$ & 83.37 & (44.93-96.99) & $0.9689 \pm 0.1679$ \\
\hline $\mathbf{P V}^{\mathrm{d}}$ & 6.20 & $(3.06-8.50)$ & $\mathbf{0 . 9 6 9 5} \pm 0.1679$ \\
\hline$G V^{d}$ & 18.95 & $(5.30-29.51)$ & $0.9697 \pm 0.1679$ \\
\hline$b^{\mathrm{d}}$ & 7.89 & $(2.25-60.08)$ & $0.9690 \pm 0.1679$ \\
\hline$c^{\mathrm{d}}$ & 0.81 & $(0.46-1.22)$ & $\mathbf{0 . 9 4 5 3} \pm 0.1679$ \\
\hline Seedling & & & $\sigma_{f}^{2}$ \\
\hline $\mathbf{H} \mathbf{1}^{\mathrm{e}}$ & 4.94 & $(4.06-6.16)$ & $27.8^{* * *}$ \\
\hline$D 1^{e}$ & 1.40 & $(1.23-1.55)$ & $25.9^{* * *}$ \\
\hline$S 1^{\mathrm{e}}$ & 0.28 & $(0.22-034)$ & $22.9 * * *$ \\
\hline $\mathbf{R} 1^{\mathrm{e}}$ & 0.16 & $(0.12-0.18)$ & $16.5^{* * *}$ \\
\hline RSR1 $^{e}$ & 0.57 & $(0.47-0.66)$ & $19.2 * * *$ \\
\hline RL1 $^{f}$ & 508.64 & $(404.62-690.12)$ & $19.16^{* *}$ \\
\hline RD1 ${ }^{f}$ & 0.45 & $(0.43-0.48)$ & $18.67 *$ \\
\hline RAP1 ${ }^{f}$ & 22.58 & $(18.56-28.63)$ & $17.13 *$ \\
\hline $\mathrm{H} 2^{\mathrm{e}}$ & 32.86 & $(22.89-37.86)$ & $27.8 * * *$ \\
\hline D2 ${ }^{e}$ & 5.62 & $(5.15-5.98)$ & $11.37 * * *$ \\
\hline$S 2^{e}$ & 7.78 & $(6.52-8.64)$ & $10.03 * * *$ \\
\hline $\mathbf{R} 2^{\mathbf{e}}$ & 2.53 & $(2.16-2.82)$ & $6.90 * * *$ \\
\hline RSR2 $^{e}$ & 0.33 & $(0.25-0.43)$ & $32.17 * * *$ \\
\hline
\end{tabular}
ables, and percentage of total variance explained by interfamily variation of seedling characteristics.

${ }^{\mathrm{a}} \mathrm{LS}$ - Straight length; WS - Straight width; WLR - Width to length ratio; AP - Projected area; AE - Ellipsoidal area; VE - Ellipsoidal volume; SW - 1000-seed weight; GC - Germination capacity; PV - Peak value; GV - Germination value; $b$ and $c-$ Weibull function parameters; $\mathrm{H}$ - Seedling height; D - Root collar diameter; S - Shoot dry weight; R - Root dry weight; RSR - Root to shoot ratio; RL - Total root length; RD - Average root diameter; RAP - Root projected area; 1 and $2-$ end of the first and of the second growing seasons, respectively.

$R e$ - repeatability; $h_{f}^{2}$ - family heritability estimate; $\sigma_{f}^{2}$ - family variance as percentage of the total variance;

$* p<0.05$;** $p<0.01$; *** $p<0.001$ using Wald $Z$ test

b75 families x 400 seeds per family

c70 families x 8 × 100 seeds per family

d 72 families $x 4$ replications x 100 seeds per family.

e 75 families $x 3$ seedlings $x 6$ blocks per family

f75 families x 1 seedling x 3 blocks per family. 
variance expressed as a percentage of the total variance, for the seed, germination and seedling characteristics. Repeatabilities for seed characteristics ranged from $0.23 \pm 0.03(\mathrm{WLR})$ to $0.98 \pm 0.004(\mathrm{SW})$, whereas heritabilities were almost the same for all the germination variables. The percentage of the total variance accounted for by the family effect ranged from $6.9 \%$ (R2) to $32.2 \%$ (RSR2) (Table 1).
Weibull parameter estimates $b$ and $c$ were significantly different between families (Table 1). The highest $b$ estimates occurred in 10 families with GC values below $66 \%$ at the end of the germination test. In contrast, the lowest $b$ values occurred in three families that had the most rapid germination with GC values exceeding $90 \%$ as early as Day 11. Figure 1 shows that even when $b$ is the same, family germination curves can have different

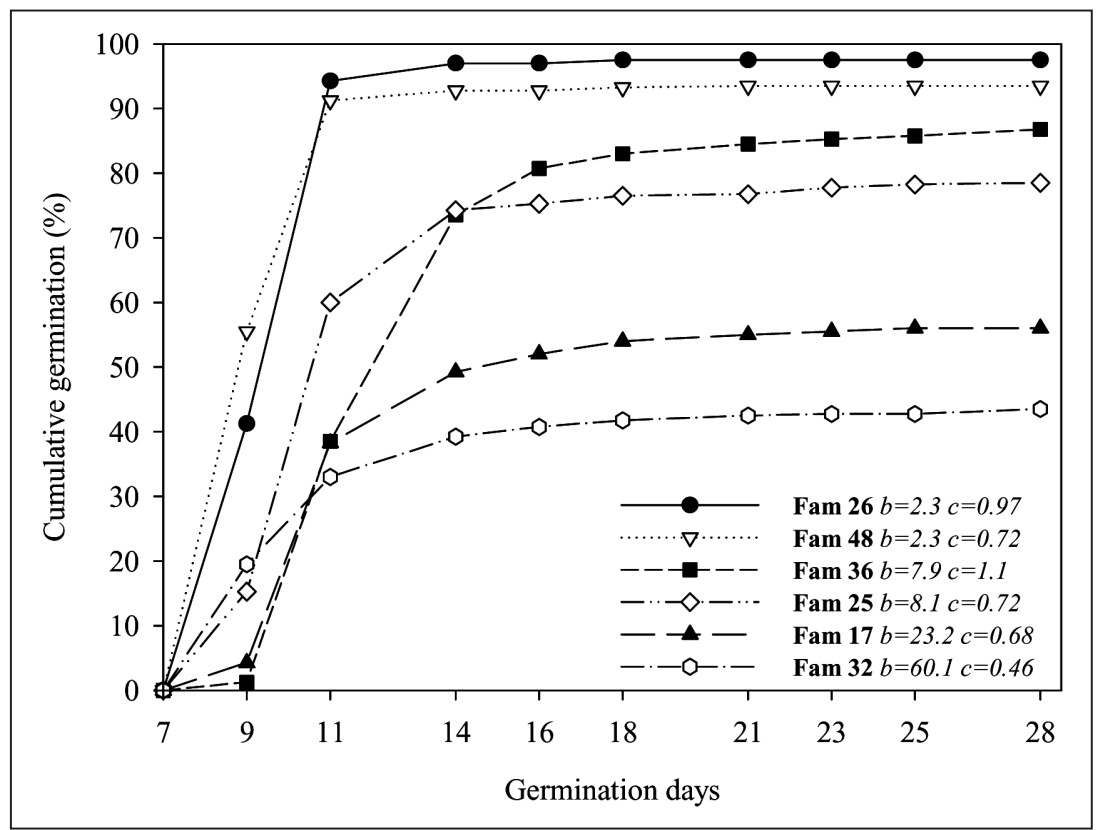

Figure 1. - Cumulative germination curves for six families of white spruce seeds chosen from 75 families because of their Weibull function $b$ parameter values: families 26 and 48 have the highest values among the 75 estimated $b$ values, families 36 and 25 have estimated $b$ values near the average $b$ value, and families 17 and 32 have the lowest estimated $b$ values. Each point is the average of four replications of 100 seeds per family.

Table 2. - Pearson correlation coefficients for white spruce seed and seedling characteristics. Correlations were estimated between family means (or Best Linear Unbiased Predictions - BLUP) for each variable.

\begin{tabular}{|c|c|c|c|c|c|c|c|c|c|c|c|c|c|}
\hline Seeds ${ }^{\mathrm{a}}$ & H1 & D1 & S1 & R1 & RSR1 & RL1 & RAP1 & RD1 & H2 & D2 & S2 & R2 & RSR2 \\
\hline $\mathbf{S W}^{\mathrm{b}}$ & $0.28^{*}$ & $0.37^{* *}$ & $0.43^{* *}$ & $0.54^{* * *}$ & 0.06 & $0.29^{*}$ & $0.30^{*}$ & -0.07 & $0.27^{*}$ & 0.13 & $0.32^{* *}$ & 0.06 & -0.19 \\
\hline $\mathbf{L S}^{\mathbf{c}}$ & 0.20 & $0.36^{* *}$ & $0.43^{* * *}$ & $0.46^{* * *}$ & -0.03 & $0.32^{* *}$ & $0.32 * *$ & -0.14 & $0.23^{*}$ & 0.11 & $0.28^{*}$ & -0.02 & -0.21 \\
\hline $\mathbf{W} \mathbf{S}^{\mathbf{c}}$ & 0.22 & $0.38^{* *}$ & $0.45^{* * *}$ & $0.50^{* * *}$ & -0.02 & $0.29^{*}$ & $0.32^{* *}$ & -0.03 & 0.22 & 0.14 & $0.35^{* *}$ & 0.01 & $-0.23^{*}$ \\
\hline$W_{L R}{ }^{c}$ & 0.02 & 0.02 & 0.01 & 0.05 & 0.02 & -0.06 & -0.01 & 0.15 & -0.02 & 0.06 & 0.10 & 0.05 & -0.03 \\
\hline $\mathbf{A P}^{\mathbf{c}}$ & 0.22 & $0.39 * *$ & $0.45^{* * *}$ & $0.49^{* * *}$ & -0.02 & $0.33^{* *}$ & $0.34^{* *}$ & -0.09 & $0.24^{*}$ & 0.14 & $0.33^{* *}$ & -0.01 & $-0.23^{*}$ \\
\hline $\mathbf{A} \mathbf{E}^{\mathbf{c}}$ & 0.22 & $0.39 * *$ & $0.45^{* * *}$ & $0.49^{* * *}$ & -0.02 & $0.32^{* *}$ & $0.34^{* *}$ & -0.09 & $0.24^{*}$ & 0.14 & $0.33^{* *}$ & -0.01 & $-0.23^{*}$ \\
\hline$V E^{\mathbf{c}}$ & 0.22 & $0.38 * *$ & $0.43^{* * *}$ & $0.48^{* * *}$ & -0.02 & $0.32^{* *}$ & $0.33^{* *}$ & -0.07 & $0.24^{*}$ & 0.14 & $0.33^{* *}$ & -0.01 & $-0.23^{*}$ \\
\hline$G^{d}$ & 0.05 & $0.26^{*}$ & 0.20 & $0.28^{*}$ & 0.07 & 0.08 & 0.11 & 0.17 & 0.06 & 0.05 & 0.04 & 0.01 & 0.01 \\
\hline$P V^{d}$ & 0.20 & $0.29^{*}$ & $0.27 *$ & $0.33^{* *}$ & 0.04 & 0.09 & 0.13 & 0.18 & 0.09 & 0.14 & 0.07 & -0.03 & -0.03 \\
\hline$V G^{d}$ & 0.17 & $0.30^{* *}$ & $0.27 *$ & $0.32^{* *}$ & 0.03 & 0.09 & 0.12 & 0.17 & 0.09 & 0.12 & 0.06 & -0.03 & -0.02 \\
\hline
\end{tabular}

a SW - 1000-seed weight; LS - Straight length; WS - Straight width; WLR - Width to length ratio; AP - Projected area; AE - Ellipsoidal area; VE - Ellipsoidal volume; GC - Germination capacity; PV - Peak value; GV - Germination value; H - Seedling height; D - Root collar diameter; S - Shoot dry weight; R - Root dry weight; RSR - Root to shoot ratio; RL - Total root length; RD - Average root diameter; RAP - Root projected area; 1 and 2 - end of the first and of the second growing seasons, respectively.

b 70 families

c 75 families

$\mathrm{d} 72$ families

$* p<0.05$; ** $p<0.01$; *** $p<0.001$. 
shapes as depicted by the variation in $c$. This is illustrated in Figure 1 by the germination curves of families $25(\mathrm{~b}=8.1)$ and $36(\mathrm{~b}=7.9)$, whose $b$ values were close to the overall average of 7.9 (Table 1). In contrast, families $25(\mathrm{c}=0.72)$ and $36(\mathrm{c}=1.1)$ differed considerably for the shape parameter $c$. The higher $c$ value for family 36 was associated with a lower cumulative germination in the early stages of the germination test (Figure 1).

Neither $b$ nor $c$, observed under laboratory conditions, significantly $(\mathrm{p}>0.05)$ influenced seedling characteristics at the end of the first and second growing seasons in the nursery (data not shown).

\section{Seed vs Seedling characteristics}

The Pearson correlation coefficients for the family means between seed and seedling characteristics are summarized in Table 2. All correlations were low to moderate ( -0.23 to 0.54$)$. SW was the seed characteristic the most often correlated with seedling characteristics. R1 seemed to be the seedling characteristic the most closely linked to seed characteristics. First (D1, S1, R1, RL1) and second (H2, S2) growing season seedling growth characteristics were significantly $(\mathrm{p}<0.05)$ and positively correlated with most of seed size-related characteristics. The correlation between seed size and rootto-shoot ratio became increasingly negative with an increase in seedling age (Table 2).

Table 3. - Results from a stepwise forward regression analysis of the family means for seedling (dependent variable, DV) regressed on selected seed characteristics (independent variable, IV). IVs entered into the model were: SW, LS, WS, and GV. Only significant models and IVs retained in the model $(p=0.15$ for entry and retention) are presented.

\begin{tabular}{|c|c|c|c|c|}
\hline $\mathrm{DV}^{\mathrm{a}}$ & IV & Partial $\boldsymbol{R}^{26}$ & $\mathbf{R}^{2 \mathrm{c}}$ & $\mathrm{p}^{\mathrm{d}}$ \\
\hline $\mathrm{HI}$ & $\begin{array}{l}S W \\
G V\end{array}$ & $\begin{array}{l}0.0810 \\
0.0332\end{array}$ & 0.1142 & $*$ \\
\hline D1 & $\begin{array}{l}L S \\
G V\end{array}$ & $\begin{array}{l}0.1334 \\
0.0690\end{array}$ & 0.2025 & $* *$ \\
\hline S1 & $\begin{array}{l}S W \\
G V\end{array}$ & $\begin{array}{l}0.1973 \\
0.0604\end{array}$ & 0.2577 & $* * *$ \\
\hline R1 & $\begin{array}{l}S W \\
G V\end{array}$ & $\begin{array}{l}0.2792 \\
0.0461\end{array}$ & 0.3252 & $* * *$ \\
\hline RL1 & $L S$ & 0.0893 & 0.0893 & * \\
\hline RAPI & $L S$ & 0.0859 & 0.0859 & $*$ \\
\hline $\mathrm{H} 2$ & $S W$ & 0.0922 & 0.0922 & * \\
\hline S2 & $W S$ & 0.1166 & 0.1166 & $* *$ \\
\hline RSR2 & $S W$ & 0.0492 & 0.0492 & * \\
\hline
\end{tabular}

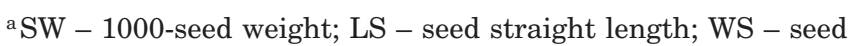
straight width; GV - germination value; $\mathrm{H}$ - seedling height; $\mathrm{D}$ - root collar diameter; $\mathrm{S}$ - shoot dry weight; $\mathrm{R}$ - root dry weight; RSR - root to shoot ratio; RL - total root length; RAP root projected area; 1 and 2 - end of the first and of the second growing seasons, respectively.

${ }^{\mathrm{b}}$ Coefficient of partial determination for each significant independent variable.

${ }^{c}$ Coefficient of determination for the final model.

$\mathrm{d} * p<0.05 ; * *<<0.01 ; * * * p<0.001$.
Table 4. - Estimated family heritabilities $\left(h_{f}^{2}\right)$ for white spruce seedling characteristics, before and after adjusting family means for seed characteristics.

\begin{tabular}{llcc}
\hline \multirow{2}{*}{$\begin{array}{c}\text { Seedling } \\
\text { characteristic }^{\text {a }}\end{array}$} & $\begin{array}{l}\text { Retained seed } \\
\text { characteristic }^{\mathrm{a}}\end{array}$ & \multicolumn{2}{c}{$\boldsymbol{h}_{f}^{2}$} \\
\hline H1 & $S W, G V$ & $0.85 \pm 0.15$ & $0.82 \pm 0.16$ \\
R1 & $S W, G V$ & $0.76 \pm 0.14$ & $0.64 \pm 0.13$ \\
H2 & $S W$ & $0.86 \pm 0.15$ & $0.85 \pm 0.16$ \\
R2 & none & $0.56 \pm 0.12$ & - \\
\hline
\end{tabular}

${ }^{a} \mathrm{SW}$ - 1000-seed weight; GV - germination value; $\mathrm{H}$ - seedling height; $\mathrm{R}$ - root dry weight; 1 and 2 - end of the first and of the second growing seasons respectively.

Stepwise multiple regression analysis revealed that the between-family variance observed during seedling development can be partially explained by a pre-existing between-family variance at the seed stage for some of the one and two-year old seedling characteristics (Table 3). Stepwise multiple regressions retained two seed characteristics for explaining family variation of H1, D1, S1 and R1 and one seed characteristic for RLl, RAP1, H2, S2 and RSR2. Results are presented in Table 3. The independent variables most frequently retained in the multiple-regression models were SW and GV. The percentage of the total seedling variance explained by the between family variance at the seed stage varied from $8.7 \%$ (RAP1 vs. LS) to $32.5 \%$ (R1 vs. SW and GV), $27.9 \%$ of which was due to SW, while GV accounted for $4.6 \%$.

Table 4 summarizes seedling family heritability estimates with and without taking into account pre-existing between-family variance at the seed stage. The seed characteristics used to adjust for the effect of seed size on variation for seedling growth were the ones previously retained by the stepwise regression. The largest decrease in heritability was achieved when $\mathrm{R} 1$ was adjusted for SW and GV.

\section{Discussion}

\section{Overall results}

Comparing the offspring of 75 open-pollinated white spruce families revealed statistically significant variation between families for all measured seed characteristics and germination variables. Morphological and physiological family differences at the seed stage explain up to $33 \%$ of the family variation observed at the one-year seedling stage and up to $12 \%$ of the family variation observed at the two-year seedling stage.

\section{Variation for Seed Morphology}

Our results demonstrated that nearly all of the variance in SW and half of the variance in seed morphological characteristics were due to the family effect. These findings agree with those reported for Pinus strobus by BEAULIEU and Simon (1995), who found that $53.9 \%$ of the variance for length of the winged seed was due to variation among families. In Douglas-fir (Pseudotsuga menziesii), ST. CLAIR and ADAMS (1991) found that $95 \%$ 
of the variance in seed weight was explained by the family variance. Meanwhile, SorEnsen and CAMPBELL (1993) showed that $59 \%$ of the variance in seed weight for Douglas-fir was explained by the family effect. Thus, the high percentage of the family variance observed in our study is consistent with results from similar studies of conifer seeds.

Seed size and weight are strongly influenced by the genotype and growing environment of the mother tree (CASTRO, 1999). In this study, the environmental effect was minimized by the use of seeds collected from grafted trees growing on a very fertile and homogenous site. However, the sampled trees were clones originating from several provenances in Ontario and Quebec that exhibited differences in growth habits (Li et al., 1993). Consequently, a portion of the family variability was likely due to morphological differences among the mother trees such as diameter (CARON et al., 1993), or heightto-diameter ratio (NolAND et al., 2006), which are the combined expression of the provenance effect, the within- provenance effect (genetic family effect) and the interaction with the environment and the other trees in the stand. Since our seed collection was limited to one production year per tree, estimates of genetic effects cannot be separated from general environment condition effects (FARMER, 1997). The proportion of the variance in seed characteristics not explained by family variability is likely due to within-tree variability. Conifer seed weight is indeed known to vary with cone size (WRIGHT, 1945) and its location within a tree (SHEN et al., 1981).

\section{Variation in Seed Germination}

Our results demonstrated that $81-89 \%$ of the variation for the three single-value germination indices and two Weibull function parameters were due to differences among families (Table 1). These high values can partly be attributed to the methods used for the germination tests. Testing germination of seedlots in an incubator minimizes non-genetic within-family variation, which has been shown to be large (SORENSEN, 2004). Reduction in this environmental variance associated with test conditions enabled us to detect genetic variation in seed germination pattern that is known to exist in conifers such as white spruce (CARON et al., 1993; KRAKOwSKI and El-Kassaby, 2005), Sitka spruce (Picea sitchensis (Bong.) Carr) (CHAISURISRI et al., 1992) and Douglas-fir (EL-KASSABY et al., 1992). For instance, EL-KASSABY et al. (1992) estimated repeatabilities of 0.80 for the rate of germination and 0.93 for the germination value, which corresponds well with values obtained in the present study. In addition, our results on germination curves are consistent with those of BRAMLETT et al. (1983) for Virginia pine (Pinus virginiana) and RINK et al. (1979) for sweetgum (Liquidambar Styraciflua L.).

\section{Seed vs. Seedling Characteristics}

Generally, weak but significant $(p<0.05)$ linear relationships were found between germination variables and seedling growth characteristics at the end of the first growing season. Seedling growth characteristics measured at the end of the second growing season were even more poorly correlated with seed germination vari- ables (Table 2). Weak correlations between germination variables and seedling characteristics in this study may be attributed to the fact that germination patterns were studied in an incubator under ideal germination conditions as opposed to variable conditions in the nursery where seedlings were grown. Despite the weakness of the correlations, our results show that the timing of seed germination influences the variation in the size of very young seedlings, which has been demonstrated in other conifers (e.g. Dunlap and BARNETT, 1983). The decline in the correlation between timing of seed germination and seedling growth during the second growing season (Table 2) suggests that the effect of seed germination on variation in seedling growth may be shortlived.

Positive significant linear relationships were found between the family means of all of the seed and oneyear-old seedling morphological characteristics except root-to-shoot ratio and average root diameter. Therefore, measuring seed morphological characteristics, in addition to the standard practice of measuring 1000-seed weight, does not provide any additional information. Correlations might have been stronger if, like LAMHAMEDI et al. (2006), we had compared individual seedling characteristics with the characteristics of the seed which it originated, instead of estimating correlations between family means of seed and seedling characteristics. However, our results are of the same order of magnitude as those found for Douglas-fir by ST. CLAIR and ADAMs (1991). At the end of the second growing season, only the relationships between seed characteristics and seedling shoot characteristics remained statistically significant (Table 2) as found for Douglas-fir by SoRENSEN and CAMPBELL (1985). KHALIL (1981) found a statistically significant regression for white spruce, where 1000-seed weight accounted for $22 \%$ of the variation in two-yearold seedling height. He concluded that seed weight and annual height growth were genetically correlated and controlled pleiotropically or by linkage. In the present study, only shoot characteristics remained significantly correlated with seed size at the end of the second growing season, therefore, the indirect effect of seed size, through its effect on one-year-old seedling size, could explain this correlation. Like many northern conifers, white spruce exhibits two forms of shoot growth. After germination, seedling growth proceeds indeterminately (Pollard, 1974), but as early as the second growing season, growth will partially be determined by the number of needle primordia formed during the bud morphogenesis at the end of the previous growing season. Bud development of young white spruce seedlings is sensitive to seedling size (POLLARD, 1974). With an average family height varying between 4.3 and $6.2 \mathrm{~cm}$ at the end of the first growing season, our tallest family could have had up to 70 more primordia than the shortest family, with the total number of primordia per bud varying from 100 to 250 (Pollard, 1974). POLLARD's (1974) correlation between needle initiation and subsequent height growth could then be used to justify that the relationship between seed characteristics and seedling height remained significant at the end of the second growing season. 
If the pre-existing between-family variance at the seed stage is taken into account, family variation at the seedling stage and family heritabilities are reduced. However, this reduction remains inferior to the standard deviation of the heritability estimate and, as previously stated, a significant fraction of the variation in seed characteristics may be of genetic origin.

\section{Conclusion}

Juvenile seedling characteristics are maternally influenced through seed size. Nevertheless, the present study does not permit partitioning of the maternal effect into genetic and environmental sources. To isolate general environmental effects from genetic effects, this experiment should be repeated for each family over several growing seasons. Adjusting for the environmental fraction of seed size is recommended because it would prevent overestimation of genetic parameters due to maternal effects. Nonetheless, in the present study which was based on a comparison of family means, a maximum of only $12 \%$ of the family differences observed at the two-year seedling stage were explained by the effect of seed size. Therefore, a selection for families with better juvenile characteristics could be envisaged without considering the maternal effect on seed size.

\section{Acknowledgments}

This study was conducted in collaboration with the Centre de production de plants forestiers (CPPFQ, Sainte Anne de Beaupré, Québec), le ministère des Ressources naturelles et de la Faune (MRNF) du Québec and the Laurentian Forestry Centre (Canadian Forest Service). The authors thank RICHARD GOHIER, LYNE Lachance, Monique Pelletier, Mario Renaud, Étienne TURGEON and SÉBASTIEN GERARDI for their technical assistance. Statistical advice was provided by LouIS Blais (DRF, MRNF) and MichÈle Bernier-Cardou (Laurentian Forestry Centre, Canadian Forest Service). We are also grateful to PHILIPPE BARADAT (retired from CIRAD-INRA AMAP, France) for his help using the Diogene software.

This network project (2004-FO-103181) was made possible due to the financial support of Fonds québécois de la recherche sur la nature et les technologies (project 2004-FO-103181 to Dr. H. MARGOLIS), the Direction Générale des pépinières et des stations piscicoles (DGPSP, MRNF), the Natural Sciences and Engineering Research Council of Canada (Doctoral Fellowship to S. CARLES) and the support of the Direction de la recherche forestière (DRF, MRNF) accorded to Dr. M. S. LAMHAMEDI and F. COLAS (projects 112310094 and 112310084), and that of the Canadian Wood Fibre Centre to Dr. J. BeAUlieU.

\section{References}

BARADAT, P. and T. LABBÉ (1995): OPEP (Diogène), un logiciel intégré pour l'amélioration des plantes pérennes. In: Cirad CP (ed) Traitements statistiques des essais de sélection. Montpellier, France, pp 303-330.
Beaulieu, J. and J.-P. Simon (1995): Variation in cone morphology and seed characters in Pinus strobus in Québec. Can. J. Bot. 73: 262-271.

BEAUlieU, J. (1996): Breeding program and strategy for white spruce in Quebec. Nat. Resour. Can., Can. For. Serv., Sainte-Foy, Quebec. Inf. Rep. LAU-X-117E, 25 p.

BECKER, W. A. (1985): Manual of quantitative genetics Fourth edition. Academic enterprises, Pullman, Washington.

Bonner, F. T. and T. R. Dell (1976): The Weibull function: a new method of comparing seed vigor. J. Seed Technol. 1: 96-103.

Bramlett, D. L., T. R. Dell and W. D. Pepper (1983): Genetic and maternal influences on virginia pine seed germination. Silvae Genet. 32: 1-4.

BROwn, R. F. and D. G. MAYER (1988): Representing cumulative germination. 2. The use of the Weibull function and other empirically derived curves. Ann. Bot. 61: 127-138.

Caron, G. E., B. S. P. Wang and H. O. Schooley (1993): Variation in Picea glauca seed germination associated with the year of cone collection. Can. J. For. Res 23: 1306-1313.

CASTRO, J. (1999): Seed mass versus seedling performance in Scots pine: a maternally dependent trait. New Phyt. 144: $153-161$.

Chaisurisri, K., D. G. W. Edwards and Y. A. El-Kassaby (1992): Genetic control of seed size and germination in Sitka spruce. Silvae Genet. 41(6): 348-355.

Corriveau, A., J. Beaulieu and G. Daoust (1991): Heritability and genetic correlations of wood characters of Upper Ottawa Valley white spruce populations grown in Quebec. For. Chron. 67(6): 698-705.

Czabator, F. J. (1962): Germination value: an index combining speed and completeness of pine seed germination. For. Sci. 8 (4): 386-396.

Dieters, M. J., T. L. White, R. C. Littel and G. R. Hodge (1995): Application of approximate variances of variance components and their ratios in genetic tests. Theor. Appl. Genet. 91: 15-24.

DunLAP, J. R. and J. P. BARNETT (1983): Influence of seed size on germination and early development of loblolly pine (Pinus taeda L.) germinants. Can. J. For. Res 13: 40-44.

El-Kassaby, Y. A., D. G. W. Edwards and A. R. TaYloR (1992): Genetic control of germination parameters in Douglas-fir and its importance for domestication. Silvae Genet. 41(1): 48-54.

FALCONER, D. S. (1981): Introduction to quantitative genetics. Longman, London, New York.

FARMER, R. E. (1997): 8. Germination genetics. In: Seed ecophysiology of temperate and boreal zone forest trees. Edited by R. E. FARMER. St Lucie Press, Delray Beach. pp. 137-154.

Grossnickle, S. C. (2005): Importance of root growth in overcoming planting stress. New For. 30: 273-294.

International Seed Testing Association (1999): International rules for seed testing. Seed Science and Technology 27 (supplement).

KHALIL, M. A. K. (1981): Correlation of juvenile height growth with cone morphology and seed weight in white spruce. Silvae Genet. 30(6): 179-181.

KHALIL, M. A. K. (1985): Heritability of juvenile characters of white spruce (Picea glauca (Moench.) Voss.) in central Newfoundland, Canada. Theor. Appl. Genet. 69: 247-251. 
KRAKowski, J. and Y. A. EL-KASSABY (2005): Lodgepole pine and white spruce germination: effects of stratification and simulated aging. Silvae Genet. 54(3): 138-144.

LAMBANY, G. and L. VEILleux (1999): Système d'imagerie informatisée appliqué au développement des racines de semis d'épinette - Note de recherche forestière $\mathrm{n}^{\circ} \mathbf{9 7}$. Direction de la recherche forestière - Ministère des Ressources naturelles du Québec.

Lamhamedi, M. S., H. Chamberland, P. Y. Bernier and F. M. TREMBLAY (2000): Clonal variation in morphology, growth, physiology, anatomy and ultrastructure ot container-grown white spruce somatic plants. Tree Phys. 20: $869-880$.

Lamhamedi, M. S., F. Colas, D. Tousignant and M. Rioux (2006): Characterization and multi-criteria selection of families for the mass cutting propagation of white spruce (Picea glauca) in Québec. In: Recent Advances in Seed Physiology and Technology, IUFRO Tree Seed Symposium. Edited by T. L. BEARDMORE and D. G. SimPson. International Union of Forest Research Organizations, Frederiction, NB Canada.

Li, P., J. Beaulieu, A. Corriveau and J. Bousquet (1993): Genetic variation in juvenile growth and phenology in a white spruce provenance-progeny test. Silvae Genet. 42(1): 52-60.

Littel, R. C., G. A. Milliken, W. W. Stroup and R. D. Wolfinger (1996): SAS System for Mixed Models. SAS Institute Inc., Cary, NC, USA.

Nienstaedt, H. and A. H. Teich (1972): The genetics of white spruce. U.S.D.A.

Nienstaedt, H. and J. C. Zasada (1990): Picea glauca [Moench] Voss White spruce. In: Silvics of North America vol. 1. Conifers - Agriculture handbook no. 654. Edited by R. M. Burns and B. H. HonkAlA. United States. Dept. of Agriculture. pp. 204-226.

Noland, T. L., W. H. PARKer and A. E. Morneault (2006): Natural variation in seed characteristics of eastern white pine (Pinus strobus L.). New For. 32: 87-103.

PAPADAKIS, J. S. (1937): Méthode statistique pour des expériences sur champ. Bull. Inst. Amélioration Plantes Salonique. 23.

Parker, W. H., T. L. Noland and A. E. Morneault (2006): The effects of seed mass on germination, seedling emergence, and early seedling growth of eastern white pine (Pinus strobus L.). New For. 32: 33-49.
Pollard, D. F. W. (1974): Seedling size and age as factors of morphogenesis in white spruce Picea glauca (Moench) Voss Buds. Can. J. For. Res. 4: 97-100.

Rink, G., T. R. Dell, G. Switzer and F. T. Bonner (1979): Use of the Weibull function to quantify sweetgum germination data. Silvae Genet. 28(1): 9-12.

RoBInson, G. K. (1991): That BLUP is a good thing: the estimation of random effects. Statistical Science 6(1): $15-32$.

Rweyongeza, D. M., F. C. YeH and N. K. DhiR (2005): Heritability and correlations for biomass production and allocation in white spruce seedlings. Silvae Genet. 54(4-5): 228-235.

Shen, H. H., D. Rudin and D. Lindgren (1981): Study of the pollination pattern in Scots pine seed orchard by means of Isozyme Analysis. Silvae Genet. 30(1): 7-15.

Simpson, J. D., B. S. P. WANG and B. I. Daigle (2004): Long-term seed storage of various Canadian hardwoods and conifers. Seed Sci. \& Tech. 32: 561-572.

SorENSEN, F. C. (2004): Environmental impacts on dormancy and germination. Canadian tree improvement association: Tree seed working group. News bulletin 39: $6-9$.

Sorensen, F. C. and R. K. CAmpbell (1985): Effect of seed weight on height growth of douglas-fir (Pseudotsuga menziesii (Mirb.) Franco var. menziesii) seedlings in a nursery. Can. J. For. Res 15: 1109-1115.

Sorensen, F. C. and R. K. CAMPBELL (1993): Seed weight seedling size correlation in coastal Douglas-fir: genetic and environmental components. Can. J. For. Res 23: 275-285.

St. Clair, J. B. and W. T. AdAms (1991): Effects of seed weight and rate of emergence on early growth of openpollinated douglas-fir families. For. Sci. 37(4): 987-997.

WANG, B. S. P. (1973): Laboratory germination criteria for red pine (Pinus resinosa Ait) seed. In: Proceedings, Association of Official Seed Analysts. pp. 94-101.

WRIGHT, J. W. (1945): Influence of size and portion of cone and seed weight on eastern white pine. J. For. 43: 817-819.

Wright, R. A., R. W. Wein and B. P. DANCiK (1992): Population differenciation in seedling root size between adjacent stands of jack pine. For. Sci. 38(4): 777-785. 